\title{
Cardiopulmonary exercise testing in cardiology: more than simple exercise testing
}

\author{
Alenka Brozina*, Damir Raljević, Tatjana Zekić Varljen, Aleksandra Šustar, Igor Klarić, \\ Vesna Pehar Pejčinović, Viktor Ivanić, Koraljka Knežević, Marko Boban, Viktor Peršić \\ Thalassotherapia Opatija - Clinic for treatment, rehabilitation and prevention of cardiovascular \\ disease, Opatija, Croatia
}

\begin{abstract}
Exercise tests are frequently used in clinical cardiology practice, as diagnostic and functional evaluation tools. Many exercise tests are designed to produce a single measurement which is relevant to a specific clinical setting (presence of ECG changes consistent with myocardial ischemia in a patient with chest pain and dyspnea; duration of the test to estimate the functional capacity of patients in cardiac rehabilitation programme). Cardiopulmonary exercise testing provides an insight into the numerous variables related to cardiorespiratory function including expiratory ventilation,
\end{abstract}

Received: $18^{\text {th }}$ Apr 2014

*Address for correspondence: Thalassotherapia Opatija, Maršala Tita 188/1, HR51410 Opatija, Croatia.

Phone: +385-51-202-600

E-mail: alenkabrozina@gmail.com pulmonary gas exchange (oxygen uptake and carbon dioxide output), along with a continuous ECG monitoring and blood pressure measurement quantifies and links metabolic, cardiovascular and pulmonary responses to exercise. Unlike standard exercise tests, data obtained from cardiopulmonary exercise testing are individualized, which allows us an accurate insight of the patient cardiorespiratory function. Today, with an increased availability of instruments for the facile measurement of exercise gas exchange, cardiopulmonary exercise testing has expanded from clinical research application to a method frequently used in diagnostic estimation of cardiac patients and in therapeutic purpose, for individualised cardiac rehabilitation programme planning.

KEYWORDS: cardiopulmonary exercise testing, exercise tests, diagnosis, cardiac rehabilitation planning.

CITATION: Cardiol Croat. 2014;9(5-6):249.

\section{Literature}

1. Wasserman K, Hansen JE, Sue DY, Stringer WW, Whipp BJ. Principles of Exercise Testing and Interpretation. 4th ed. Philadelphia: Lippincott Williams \& Wilkins; 2005.

2. Carvalho VO, Mezzani A. Aerobic exercise training intensity in patients with chronic heart failure: principles of assessment and prescription. Eur $\mathrm{J}$ Cardiovasc Prev Rehabil. 2011;18(1):5-14.

3. Balady G, Arena R, Sietsema KE, et al. American Heart Association scientific statement. American Heart Association Exercise, Cardiac Rehabilitation, and Prevention Committee of the Council on Clinical Cardiology; Council on Epidemiology and Prevention; Council on Peripheral Vascular Disease; Interdisciplinary Council on Quality of Care and Outcomes Research. Clinician's Guide to cardiopulmonary exercise testing in adults: a scientific statement from the American Heart Association. Circulation. 2010;122:191-225. 